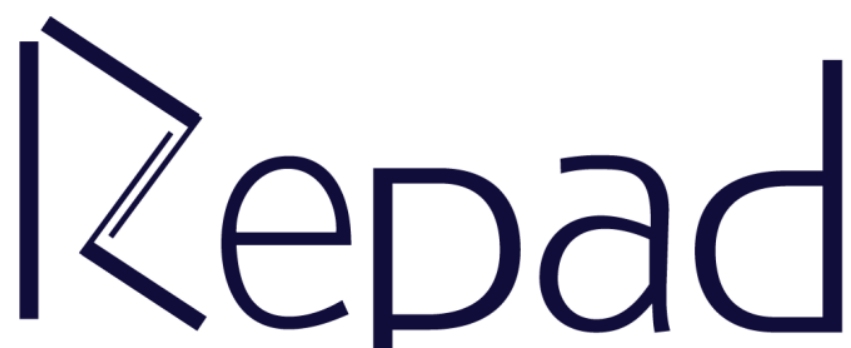

Vol. 2, n. 3, Dezembro/2018

Revista Estudos e

Pesquisas em Administração

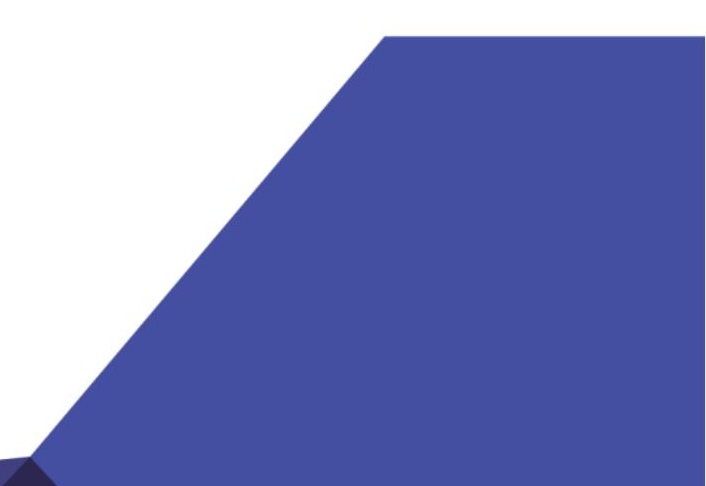




\title{
UMA REFLEXÃO DOS ARTIGOS SOBRE FENOMENOLOGIA PUBLICADOS NA SCIENTIFIC PERIODICALS ELETRONIC LIBRARY - SPELL
}

Ednéia Avelar Ogawa

Universidade Federal de Mato Grosso https://orcid.org/0000-0002-0074-8890

Evelin Caroline de Paula Universidade Federal de Mato Grosso https://orcid.org/0000-0003-0991-9833

\section{RESUMO}

O uso da fenomenologia sobre os estudos ainda é algo em debate, devido às adaptações necessárias do campo filosófico para o campo empírico e sua complexidade de informações e metodologias. Entretanto, não se pode negar a riqueza desse método para investigações que buscam conhecer o aspecto subjetivo da relação entre os seres humanos e seus espaços vividos, ou seja, as essências dos fenômenos. Foi tratado inicialmente uma breve contextualização teórica sobre a fenomenologia, para posteriormente mostrar um panorama dos artigos que utilizaram esse método em suas pesquisas. Este estudo objetivou descrever a fenomenologia na abordagem da pesquisa científica, fazendo um levantamento dos artigos encontrados na base da SPELL nos anos 2000 a 2018, enfatizando a importância deste método nos estudos organizacionais. Utilizou como procedimento metodológico pesquisas em referenciais bibliográficos e uma pesquisa no banco de dados da SPELL (Scientific Periodicals Eletronic Library) para o levantamento de artigos que continham, em seus resumos ou em seus títulos, a palavra "fenomenologia". Foram encontrados 42 (quarenta e dois) artigos relacionados ao tema pesquisado, entretanto 1 (um) deles não seguiu os critérios analisados.

Palavras-chave: Fenomenologia. Estudo bibliográfico. Base de dados.

\section{A REFLECTION OF THE ARTICLES ON PHENOMENOLOGY PUBLISHED IN THE SCIENTIFIC PERIODICALS ELETRONIC LIBRARY - SPELL}

\begin{abstract}
The use of phenomenology over studies is still something of a debate, due to the necessary adaptations from the philosophical field to the empirical field and its complexity of information and methodologies. However, we cannot deny the richness of this method for investigations that seek to know the subjective aspect of the relationship between human beings and their lived spaces, that is, the essences of phenomena. It was initially treated a brief theoretical contextualization about phenomenology, to later show a panorama of the articles that used this method in their research. This study aimed to describe the phenomenology in the approach to scientific research, making a survey of the articles found in the base of SPELL in the years 2000 to 2018, emphasizing the importance of this method in organizational studies. He used as a methodological procedure research on bibliographic references and a search in the SPELL (Scientific Periodicals Electronic Library) database for the collection of articles that contained in the abstracts or in their titles the word
\end{abstract}


"phenomenology". There were 42 (forty-two) articles related to the researched topic, however 1 (one) of them did not follow the criteria analyzed.

Keywords: Phenomenology. Bibliographic study. Data base.

\section{CONSIDERAÇÕES INICIAIS}

A fenomenologia analisa o comportamento humano a partir das experiências individuais, considerando aspectos significativos da existência. Desta forma, consiste em estudar a essência das coisas e como são percebidas no mundo. Sendo assim, os fenômenos só devem ser pensados a partir das percepções mentais de cada ser humano. Alguns dos principais autores filósofos desse método foram Maurice Merleau-Ponty e Edmund Husserl.

Então, compreende-se o mundo através das experiências vividas pelos indivíduos, procurando aprofundar o significado da existência humana, valorização do sujeito, construção do conhecimento, foco na pesquisa qualitativa, compreensão e interpretação do "EU". Porém, este método se torna muitas vezes frágil, devido a sua complexidade.

Este estudo objetivou descrever a fenomenologia na abordagem da pesquisa científica, fazendo um levantamento dos artigos encontrados na base da SPELL nos anos entre 2000 a 2018, enfatizando a importância deste método nos estudos organizacionais. Foram encontrados 42 (quarenta e dois) artigos relacionados ao tema pesquisado, entretanto 1 (um) deles não seguiu os critérios analisados.

A pesquisa dentro desta linha fenomenológica possui abordagem qualitativa de caráter descritivo, o que possibilita reflexão e discussão do tema, assim, o intuito reforça a ideia de que a pesquisa qualitativa seja a mais apropriada para a presente investigação (MOURA; BITENCOURT, 2006).

Para Marconi e Lakatos (1999), a abordagem qualitativa se trata de uma pesquisa que tem como objetivo, analisar e interpretar aspectos mais profundos, descrevendo a complexidade do comportamento humano e ainda fornecendo análises mais detalhadas sobre as investigações, atitudes e tendências de comportamento.

A fenomenologia amplia o envolvimento do pesquisador na prática estudada (PIMENTEL; NOGUEIRA, 2018), e por meio desta, poderá surgir novas possibilidades de investigação organizacional, pois é capaz de oferecer uma visão distinta dos fenômenos administrativos, o que vai além da concepção originada pelo emprego do paradigma funcionalista (BOAVA; MACEDO, 2011).

Portanto, a fenomenologia transcende o limite do individual, pois se fundamenta na consciência da existência do outro, uma vez que estuda essências. Se torna um método importante, porém complexo para se utilizar nas pesquisas científicas, pois ao analisar as experiências vividas, passa a ter uma visão global de existência, de vivências, de olhares, de percepções, conseguindo assim fazer uma reflexão de temas relevantes, o que torna interessante aos pesquisadores, pois exerce um desafio ao pesquisador. Esse tipo de método enriquece uma pesquisa, pois é capaz de sentir e levar em consideração as opiniões de sujeitos envolvidos nos processos estudados, não se limitando a nenhum procedimento prédefinido/estabelecido.

\section{FENOMENOLOGIA}

Segundo os autores Boava e Macedo (2011, p. 470), a fenomenologia "é formada pelos termos gregos phainomenon ( $(\alpha$ vó $\mu \varepsilon v o v)+\operatorname{logos}(\lambda o ́ \gamma o \varsigma)$. Phainomenon é o fenômeno, uma aparição, aquilo que se mostra. Logos é o estudo, a razão, o discurso". Com isso, é 
caracterizada por tudo aquilo que se mostra por meio da consciência. Desta forma, a fenomenologia busca pela compreensão dos significados da experiência vivida e, nesse processo, o pesquisador é orientado para o fenômeno que está sendo investigado e para interpretar as percepções encontradas, por meio da hermenêutica, utilizando um texto ou alguma forma simbólica. Busca-se compreender o mundo como vivido pelas pessoas, visando à elucidação de aspectos referentes à natureza de sua experiência vivida.

A hermenêutica reconhecerá que o pensamento está situado desde seu início, sendo um pensamento comprometido, uma vez que sempre haverá hipóteses para se filosofar, como a própria existência, que não é algo abstrato. Sendo assim, a fenomenologia em seu aspecto de hermenêutica busca interpretar esta existência, este pensamento situado, onde a existência é pautada de reflexão, e assim através desta, tentar colocar de maneira clara as estruturas desta existência e sua significação (SILVA, 2013).

É um método de pesquisa qualitativa, orientado para os significados da existência humana. A fenomenologia não está preocupada com os aspectos factuais do estado das coisas, mas com a natureza do fenômeno como significativamente experienciado (GODOI et al., 2006). Conforme Miranda (2010), o alemão Edmund Husserl (1859-1938), no final do século XIX, iniciou a corrente filosófica que analisa os fenômenos, ou seja, aquilo que se mostra sob a ótica da subjetividade, sendo ela a fenomenologia.

De acordo com Souza (2013, p. 35), “[..]a Fenomenologia foi originalmente pensada como método rigoroso voltado ao estudo da subjetividade[..]", na época em que o pensamento positivista prevalecia, Husserl insatisfeito buscou estudar aos fenômenos por meio das vivências humanas, desta forma, tudo que a consciência manifestava à luz de todo o período de existência.

Para os autores Boava e Macedo (2011, p.471):

Na virada do século XIX para o século XX, Husserl (1999a, 1999b) publicou a obra Logische untersuchungen (Investigações lógicas), trazendo novos significados para uma antiga palavra, com impactos para a filosofia e para a ciência. Nesse trabalho, Husserl (1999a, 1999b) causou grande polêmica ao atacar o psicologismo na lógica, abordagem centrada no emocional humano, minimizando sua consciência racional, ao propor uma reorientação do pensamento puro. A intenção foi estabelecer uma base epistemológica para a filosofia, que a convertesse numa ciência do rigor. Para isso, criou o chamado método fenomenológico. Assim, disse que a consciência é a condição sine qua non de qualquer conhecimento e que é intencional (toda consciência é consciência de algo).

Então, as investigações de Husserl procuram recuperar um sentido original daquilo que os gregos nomearam como fenômeno, ou seja, como aquilo que se mostra. Ele acreditava que a fenomenologia seria a autêntica filosofia, capaz de tornar clara as essências e os domínios da experiência. Portanto, a fenomenologia é o estudo da estrutura daquilo que experienciamos, a partir de nossas percepções, compreende-se como algo original, como o retorno às coisas mesmas.

Nessa perspectiva, a fenomenologia possibilita a compreensão da experiência vivida como outras metodologias não consegue fazer. Explica os aspectos mais profundos de um fenômeno, de uma situação, atentando as sensações e emoções. Através da experiência real dos indivíduos oferece a possibilidade para compreender a experiência real das pessoas, o que esta experiência significa para os indivíduos e as implicações que essas experiências trazem (ANTHEA, 2015 apud SIANI et al., 2016). 
Segundo Husserl, a fenomenologia era entendida como uma forma nova, porém, fundamental de fazer filosofia e todos os ramos da filosofia têm fundamentos na fenomenologia. Estar entrando em contato diretamente com as "coisas próprias" dava destaque à experiência de vida, deixando de lado especulações metafísicas e abstratas (SILVEIRA, 2012).

A fenomenologia começou na filosofia, e a transição deste para a pesquisa empírica em outras áreas, exige adaptações que diversos autores têm citado em seus estudos, fazendo propostas de princípios e passos para a realização de uma pesquisa fenomenológica. Entretanto é complexo construir uma regra que possa seguir dentro deste método, uma vez que neste, o pesquisador deve ter um posicionamento de se livrar de todos os conceitos e conhecimentos que tem a respeito do objeto de estudo. Este processo recebe o nome de "epochê", onde há uma suspensão do juízo, onde deixa-se em parênteses as opiniões a respeito do fenômeno, para que possa avaliá-lo em sua essência (MEDEIROS et al., 2011)

A redução fenomenológica "epoché" é o processo pelo qual tudo que é informado pelos sentidos é mudado pela experiência da consciência, ou seja, a pessoa está consciente de algo. Tudo constitui nossas experiências de consciência, todas as experiências vividas. Com isso é um aspecto fundamental para alcançar as essências no método husserliano. De acordo com Silva (2013, p. 72):

É uma suspensão do juízo, em que a realidade, como concebida pelo senso comum, é colocada entre parênteses. A redução implica uma atitude fenomenológica, conforme Husserl, contrária a atitude natural, do senso comum. A epoché busca encarar o mundo sob o aspecto do fenômeno, e com isso se tem uma redução à consciência, buscando as essências.

Epoché como defendido anteriormente, é colocar em suspensão uma ideia, ou seja, uma pesquisa qualitativa e interpretativa não perde seu caráter, porém a visão de mundo do pesquisador não afeta a visão de mundo dos entrevistados (SILVEIRA et al., 2012).

Segundo Santos e Souza (2015), Husserl aborda em seus estudos o conhecimento humano destacando a percepção, ou seja, o mesmo destaca que estamos em contato através das sensações com o mundo físico que é percebido por nós. Assim, somos capazes de perceber e compreender o que acontece ao nosso redor. A percepção é entendida como algo complexo para obter a informação, porém é o caminho que utiliza nossos sentidos para posteriormente apreender essa informação na consciência.

A Fenomenologia, conforme foi a princípio proposta por Husserl, tem como propósito o estudo da manifestação dos fenômenos à consciência. Este se dá através das diferentes vivências de cada indivíduo e estas são compostas por lembranças, imaginação e reflexão, além das experiências de vida diária de cada pessoa. Sendo assim, esses se tornam componentes de nossa estrutura transcendental na percepção dos fenômenos (BELLO, 2004 apud SOUZA, 2017).

Husserl propõe a "volta às coisas mesmas", interessando-se pelo puro fenômeno tal como se torna presente, ou seja, como ele se mostra à consciência, evocando um entendimento de cunho filosófico para a percepção. Sendo assim, a apreensão, a análise e a descrição que gera nossa consciência constituem, desse modo, o objeto (SANTOS; SOUZA, 2015).

Nesse sentido, com a abordagem fenomenológica não se deve preocupar com o mundo externo, na forma como ele existe, mas na maneira como o fenômeno existe para cada pessoa. Somente assim, é possível interpretar determinadas situações e resolver os problemas dos fenômenos individuais. Uma vez que o ser humano é singular e possui uma experiência única de vida. Portanto, sua compreensão é complexa. 


\section{PROCEDIMENTOS METODOLÓGICOS}

O presente trabalho consiste em uma pesquisa do tipo levantamento, desenvolvida a partir de material já elaborado, localizado em periódicos, livros, sites, dissertações e teses das áreas de geografia, administração, turismo, finanças, psicologia, entre outras, para uma fundamentação teórica consistente sobre o tema fenomenologia.

Por meio deste levantamento, buscou-se uma base para realizar as reflexões acerca do método fenomenológico, que tem sido um campo interessante nas ciências humanas e sociais, uma vez que este traz grande conhecimento para o crescimento profissional e pessoal, utilizando da análise dos fenômenos, por meio da subjetividade e reflexão do ser.

Utilizou-se a base de dados da SPELL (Scientific Periodicals Eletronic Library) para o levantamento de artigos que continham, em seus resumos ou em seus títulos, a palavra "fenomenologia". O levantamento foi realizado em novembro de 2018 e identificou 42 (quarenta e dois) artigos, sendo que ao realizar o estudo e análise destes, pode-se notar que 1 (um) deles não possuía os critérios solicitados do tema abordado.

Desta forma, para a construção deste trabalho foi necessário um caminho metodológico para alcançar o objetivo da pesquisa. O resumo dos procedimentos percorridos para o desenvolvimento deste estudo está indicado na Figura 1.

Figura 1. Desenho Metodológico

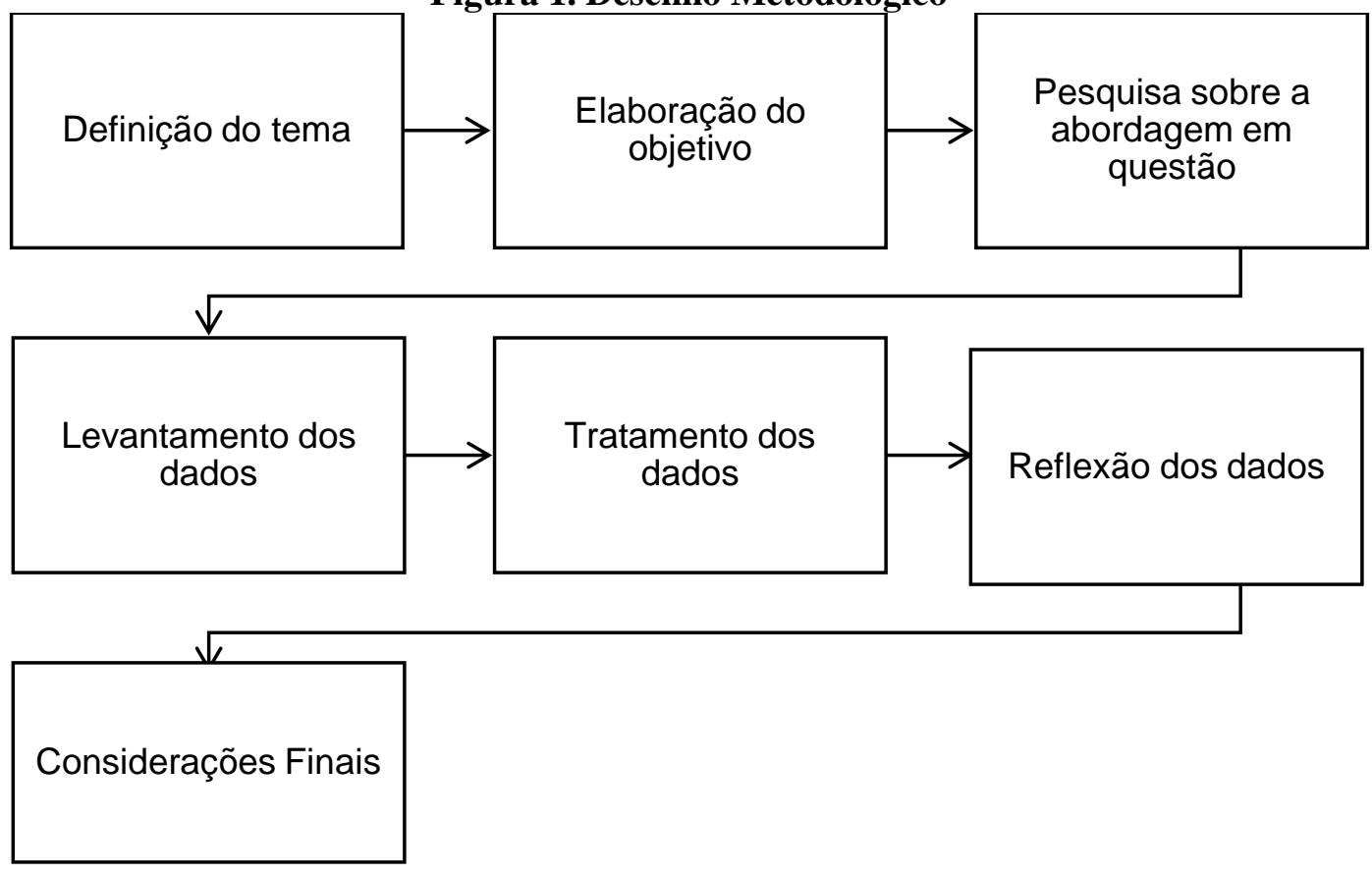

Fonte: Elaborado pelas autoras, 2018

Conforme o desenho metodológico, a definição do tema ocorre a partir da importância do método fenomenológico para os estudos organizacionais. Com isso surgiu o objetivo: descrever a fenomenologia na abordagem da pesquisa científica, fazendo um levantamento dos artigos encontrados na base da SPELL nos anos 2000 a 2018, enfatizando a importância deste método nos estudos organizacionais. Para auxiliar toda essa estruturação se fez necessário seguir todos os passos citados acima. 


\section{RESULTADOS E DISCUSSÕES}

No mês de novembro de 2018, foi realizada uma pesquisa na base de dados da SPELL para levantamento de artigos que continham, em seus resumos ou em seus títulos, a palavra "fenomenologia". Foram identificados 42 (quarenta e dois) artigos, entretanto ao observar mais especificamente cada um, foi constatado que 1 (um) deles não se enquadrava no método em estudo. Sendo assim, a análise e a apresentação dos dados são baseadas em 41 (quarenta e um) artigos.

Os artigos catalogados eram referentes aos anos 2000 a 2018. Em 2000 e 2002, foram encontrados apenas 1 (um) artigo, em cada ano. Em 2004, foram encontrados 4 (quatro) artigos. Em 2007, foram encontrados 3 (três) artigos. Em 2008 e 2009, 2 (dois) artigos cada ano. Em 2010, 4 (quatro) artigos. Em 2011, 3 (três) artigos. Em 2012, 4 artigos. Em 2013, 3 (três) artigos. Em 2014, 4 (quatro) artigos. Em 2015, 1 (um) artigo. Em 2016, 5 (cinco) artigos. Em 2017, 3 (três) artigos e no ano de 2018, 1 (um) artigo. Os anos não citados, entre as datas mencionadas anteriormente, não apresentaram artigos no banco de dados da SPELL conforme os critérios estabelecidos na busca. Desta forma, segue o Gráfico 1 para demonstrar os dados citados anteriormente.

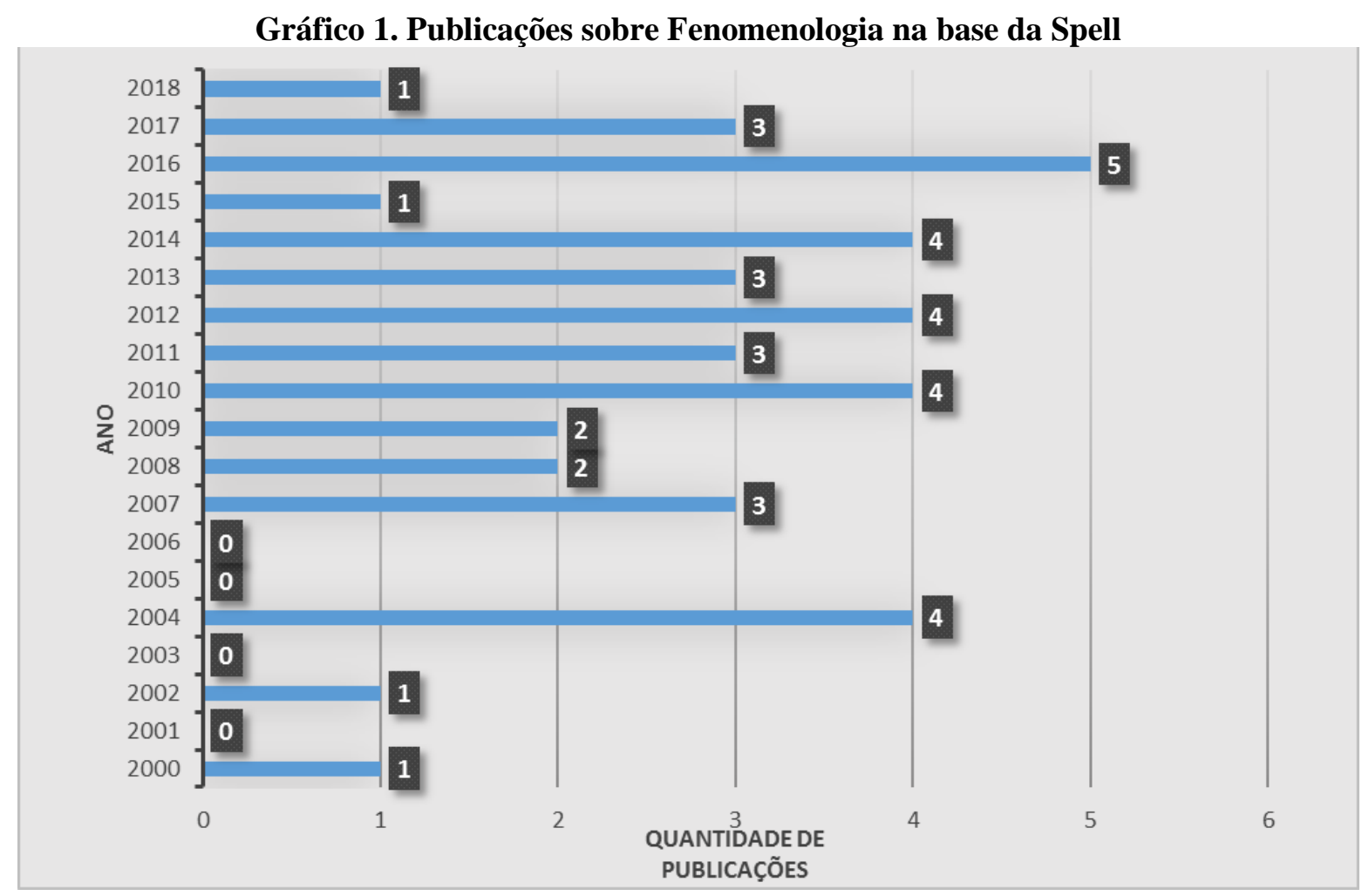

Fonte: Elaborado pelas autoras, 2018

Os resultados são apresentados buscando sistematizar o panorama das publicações em fenomenologia, percebendo que o maior número de publicações a respeito foi no ano de 2016, constando 5 (cinco) artigos nesse período.

Os artigos foram publicados nas revistas O\&S - Revistas Organizações e Sociedades, Remark - Revista Brasileira de Marketing, Revista Pensamento Contemporâneo em Administração, Revista de Ciências da Administração, Revista Caderno Virtual de Turismo, Revista FACES, Revista Capital Financeiro, Revista de Administração UNIMEP, 
Revista Farol, Revista NAVUS, Revista Alcance, Revista Gestão e Planejamento, Revista Turismo em Análise, Revista RIAE, Revista Rosa dos Ventos, Revista Desafio, Revista de Administração Mackenzie - RAM, Revista Brasil de Gestão de Negócios, Revista Administração: Ensino e Pesquisa, Revista RAC, Revista Cadernos EBAPE, Revista Rebrae, Revista Turismo, Visão e Ação, Revista Pensar Contábil, Revista Administração da Pesquisa, Revista RAU, Revista ERA, Revista Administração MADE, Revista Contabilidade \& Finanças, Revista Brasileira de Gestão de Negócios (FECAP), Revista Catarinense da Ciência Contábil (CRCSC), Revista de Administração e Revista de Administração e Inovação (RAI), conforme Tabela 1.

Tabela 1. Revistas com Publicações sobre Fenomenologia na base da Spell

\begin{tabular}{|l|l|}
\hline \multicolumn{1}{|c|}{ Revista } & $\begin{array}{c}\text { Quantidade de } \\
\text { Publicações }\end{array}$ \\
\hline Administração: Ensino e Pesquisa & 1 \\
\hline Alcance & 1 \\
\hline Administração da Pesquisa & 1 \\
\hline Cadernos EBAPE.BR (Escola Brasileira de Educação Pública e Empresas) & 3 \\
\hline Caderno Virtual de Turismo & 1 \\
\hline Desafio & 1 \\
\hline FACES & 2 \\
\hline FAROL & 1 \\
\hline Gestão e Planejamento & 1 \\
\hline NAVUS & 1 \\
\hline O\&S - Revista Organizações e Sociedades & 2 \\
\hline Pensar Contábil & 1 \\
\hline Pensamento Contemporâneo em Administração & 1 \\
\hline RAC - Revista de Administração Contemporânea & 3 \\
\hline RAI - Revista de Administração e Inovação & 1 \\
\hline RAE - Revista de Administração de Empresas & 2 \\
\hline RAM - Revista de Administração Mackenzie & 1 \\
\hline Rebrae & 1 \\
\hline Remark - Revista Brasileira de Marketing & 1 \\
\hline Revista Administração Made & 1 \\
\hline Revista Brasil de Gestão de Negócios & 1 \\
\hline Revista Brasileira de Gestão de Negócios - FECAP & 1 \\
\hline Revista Capital Financeiro & 1 \\
\hline Revista Catarinense de Ciência Contábil (CRCSC) & 1 \\
\hline Revista Contabilidade e Finanças & 1 \\
\hline Revista de Administração & 1 \\
\hline Revista de Administração UNIMEP - RAU & 2 \\
\hline Revista de Ciências da Administração & 1 \\
\hline RIAE & 1 \\
\hline Rosa dos Ventos & 1 \\
\hline Turismo em Análise & $\mathbf{4 1}$ \\
\hline Turismo, Visão e Ação & \\
\hline TOTAL & 1 \\
\hline & \\
\hline
\end{tabular}

Fonte: Elaborado pelas autoras, 2018

Após tratamento de dados, percebeu-se que as revistas que mais publicaram artigos sobre o tema fenomenologia foram o Cadernos EBAPE.BR (Escola Brasileira de Educação 
Pública e Empresas) e a RAC (Revista de Administração Contemporânea), tendo até o presente momento 3 (três) publicações em cada uma dessas revistas. A temática em estudo ainda é pouco publicada nas revistas, pois é um método, como dito anteriormente, complexo; porém, percebe-se que as áreas de gestão, administração, contábil e turismo têm feito mais pesquisas sobre percepções e experiências vividas, tentando uma aproximação maior com o fenômeno estudado, o que tem aumentado a compreensão e o relacionamento interpessoal dentro das organizações.

A seguir, encontra-se o Gráfico 2 e Gráfico 3 que representam a quantidade de publicações por Instituições de Ensino Superior (IES).

\section{Gráfico 2. Quantidade de Publicações por Instituições de Ensino Superior (IES) - Parte 1}

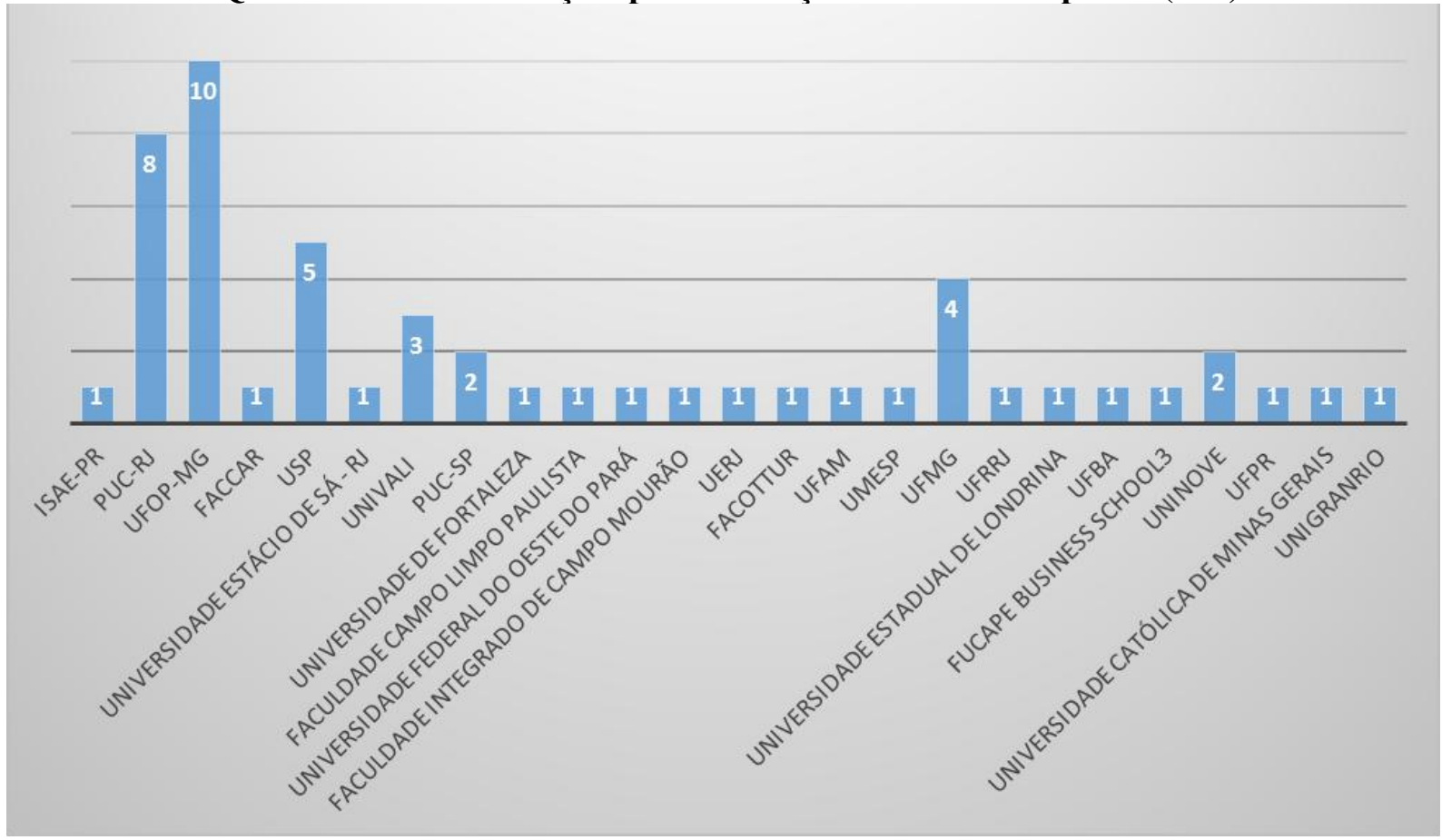

Nota-se, que nessa primeira parte que representa a Quantidade de Publicações por Instituições de Ensino Superior (IES), a que teve mais publicações foi a Universidade Federal de Ouro Preto de Minas Gerais (UFOP-MG), na qual encontram-se 10 (dez) publicações sobre fenomenologia. Pode-se também salientar a Pontifícia Universidade Católica do Rio de Janeiro (PUC-RJ) com 8 (oito) publicações sobre a abordagem em questão. Foram 49 (quarenta e nove) Instituições de Ensino Superior (IES), tratadas no presente estudo, nas quais, são distribuídas entre os 41 (quarenta e um) artigos identificados. Percebe-se também, que ocorre a união de várias Instituições de Ensino Superior (IES), para realizar os artigos. Com isso, em apenas 1 (um) estudo tende-se a encontrar distintas Instituições de Ensino Superior (IES) e consequentemente as participações das mesmas repetem-se em artigos variados sobre fenomenologia. 
Gráfico 3. Quantidade de Publicações por Instituições de Ensino Superior (IES) - Parte 2

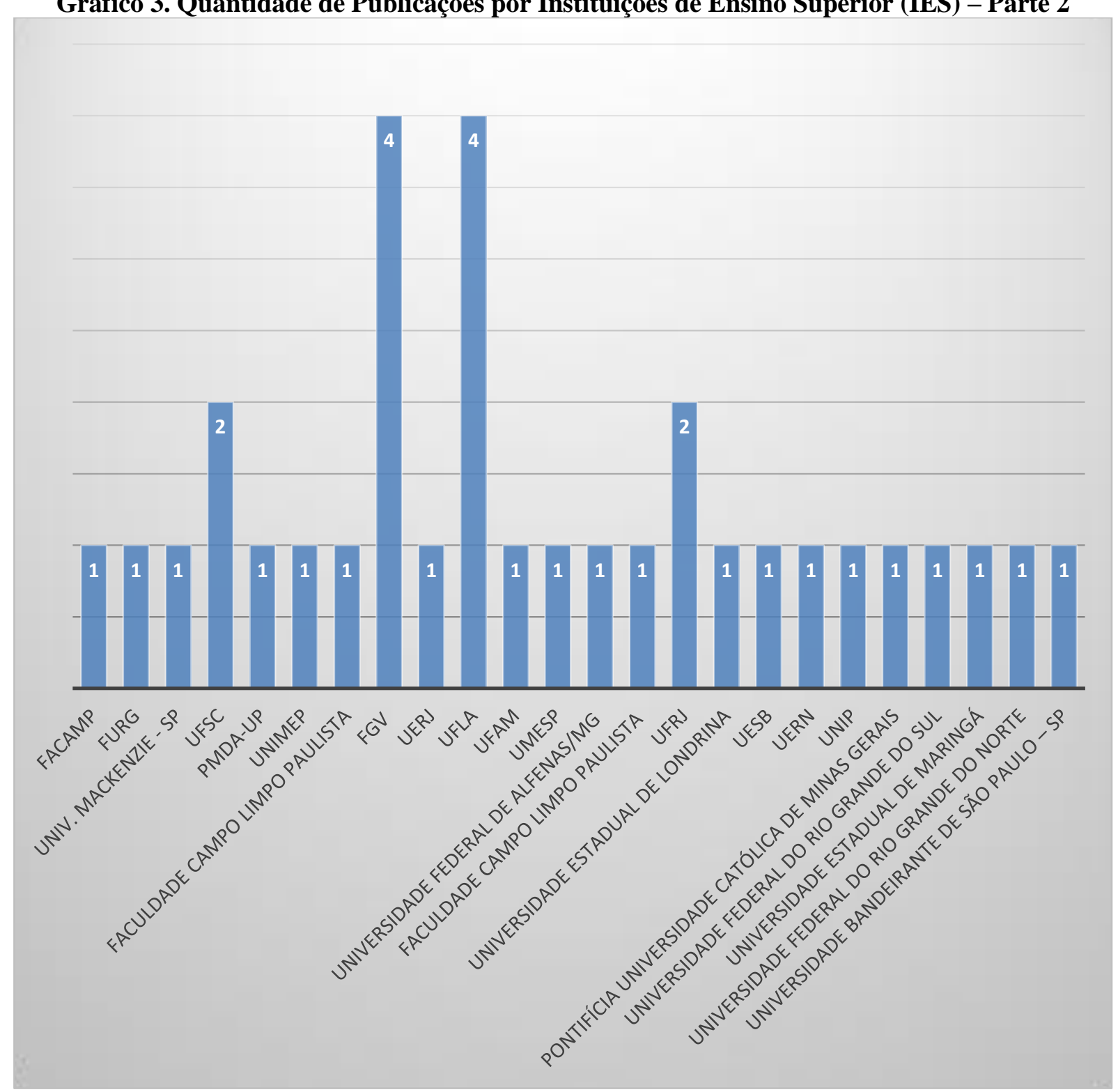

Fonte: Elaborado pelas autoras, 2018

Observa-se, que nessa segunda parte que representa a Quantidade de Publicações por Instituições de Ensino Superior (IES), as duas Instituições de Ensino Superior (IES) que tiveram mais publicações sobre fenomenologia foram a Fundação Getúlio Vargas (FGV) e a Universidade Federal de Lavras (UFLA), nas quais encontram-se 4 (quatro) publicações sobre a abordagem em cada instituição. A seguir, encontra-se o Gráfico 4 e Gráfico 5 que representam a quantidade de publicações por Autores. 


\section{Gráfico 4. Quantidade de Publicações por Autores - Parte 1}

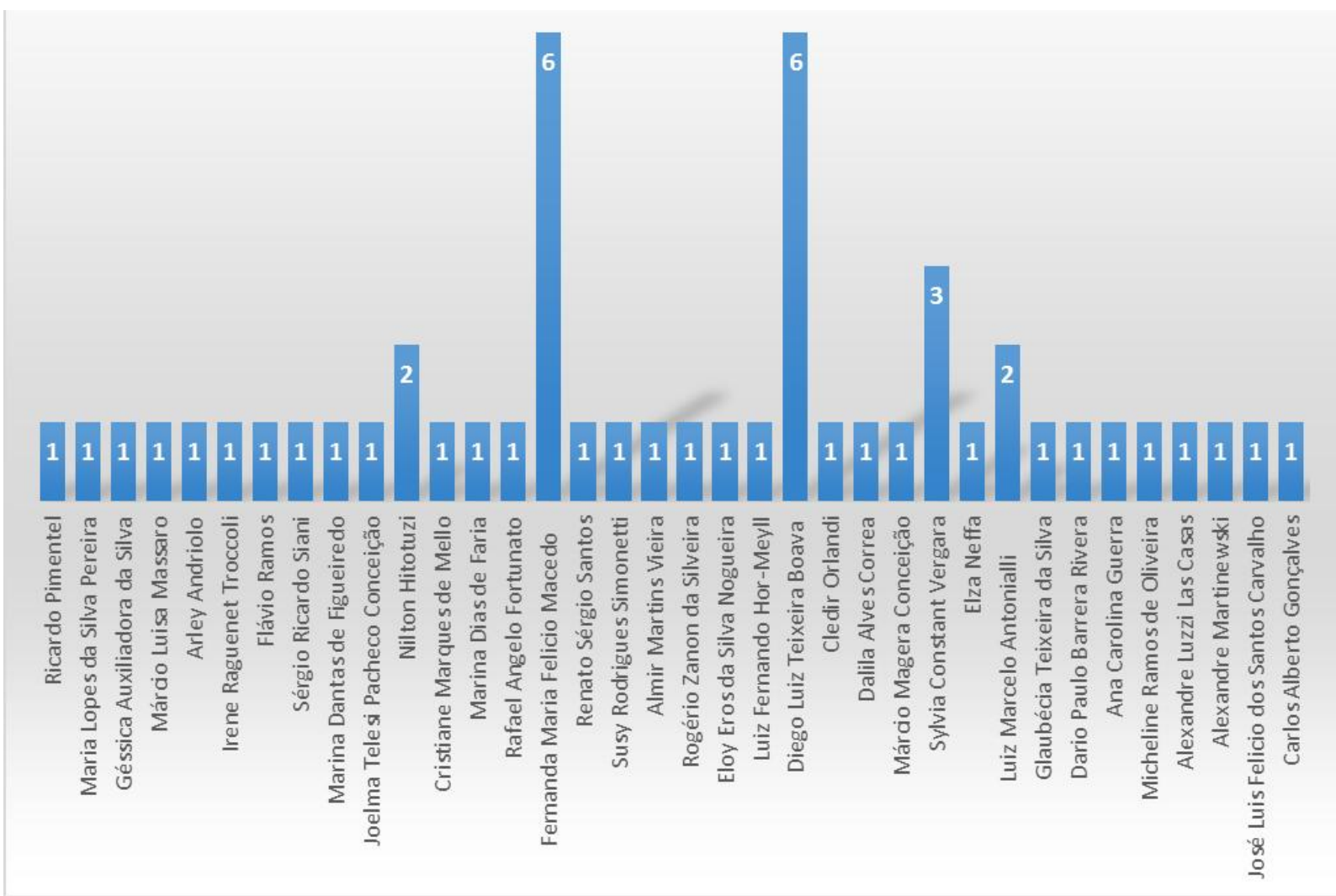

No que se refere nessa primeira parte sobre a Quantidade de Publicações por Autores, 2 (dois) foram os responsáveis pelo maior número de publicações. Desta forma, Fernanda Maria Felicio Macedo e Diego Luiz Teixeira Boava, tiveram cada um, 6 (seis) estudos científicos publicados sobre fenomenologia. Foram 70 (setenta) autores encontrados no levantamento de dados em questão. Ressalta-se para melhor compreensão que nos 41 (quarenta e um) artigos tratados, os grupos de autores são encontrados de formas distintas, ou seja, em apenas 1 (um) artigo pode-se ter, 2 (dois), 3 (três) e 4 (quatro) participantes.

Nessa perspectiva, na segunda parte sobre a Quantidade de Publicações por Autores 1 (um) autor foi o que teve o maior número de publicações. Com isso, Paulo Roberto Maisonnave publicou 2 (dois) estudos científicos sobre fenomenologia. 


\section{Gráfico 5: Quantidade de Publicações por Autores - Parte 2}

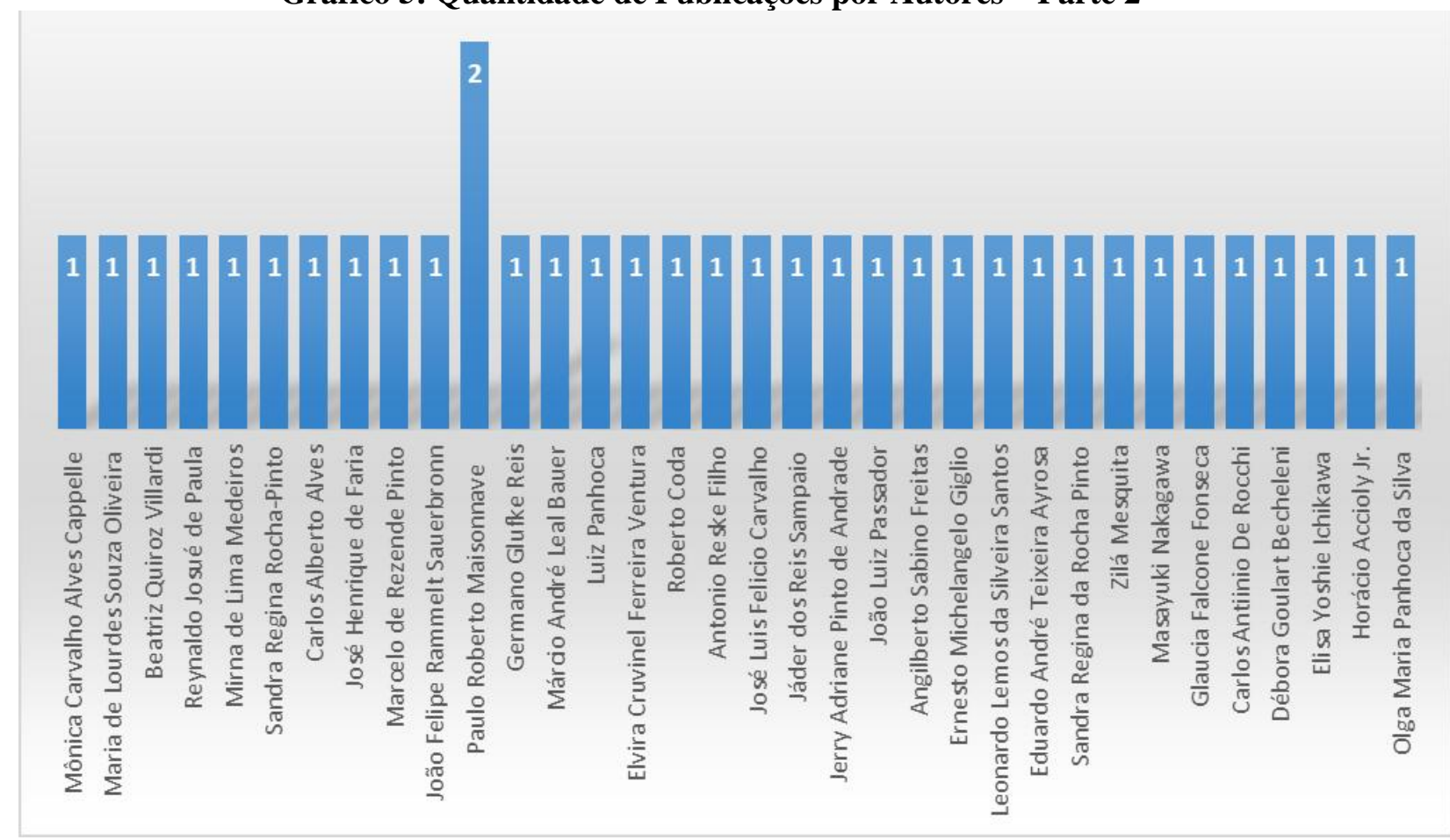

Fonte: Elaborado pelas autoras, 2018

Observa-se no Quadro 1, referente às Categorias de Identificação, que os estudos realizados sobre fenomenologia são caracterizados por sua estrutura qualitativa, entretanto também pode-se encontrar o método misto, ou seja, trabalhando a questão qualitativa e quantitativa. Para facilitar a compreensão desta abordagem, vários autores utilizaram um modelo teórico em suas publicações. Conforme o objetivo da pesquisa, os autores seguiram a abordagem teórica-empírica ou somente teórica.

A categoria temática principal dos artigos analisados foram estudos organizacionais, identificada com maior frequência nas publicações. No que se refere ao método utilizado nas pesquisas, dos 41 (quarenta e um) artigos, notou-se que, 39 (trinta e nove) são classificados como qualitativos e 2 (dois) misto. Sobre a estruturação do referencial teórico dos estudos, 9 (nove) seguiram correntes teóricas e 32 (trinta e dois) usaram conceitos.

Em relação à abordagem de pesquisa, 24 (vinte e quatro) artigos são teóricos e 17 (dezessete) artigos são teóricos-empíricos. Sobre o modelo teórico, 26 (vinte e seis) artigos usaram um modelo teórico em sua estrutura e 15 (quinze) não usaram. 
Quadro 1. Categorização dos artigos sobre fenomenologia publicados na Spell

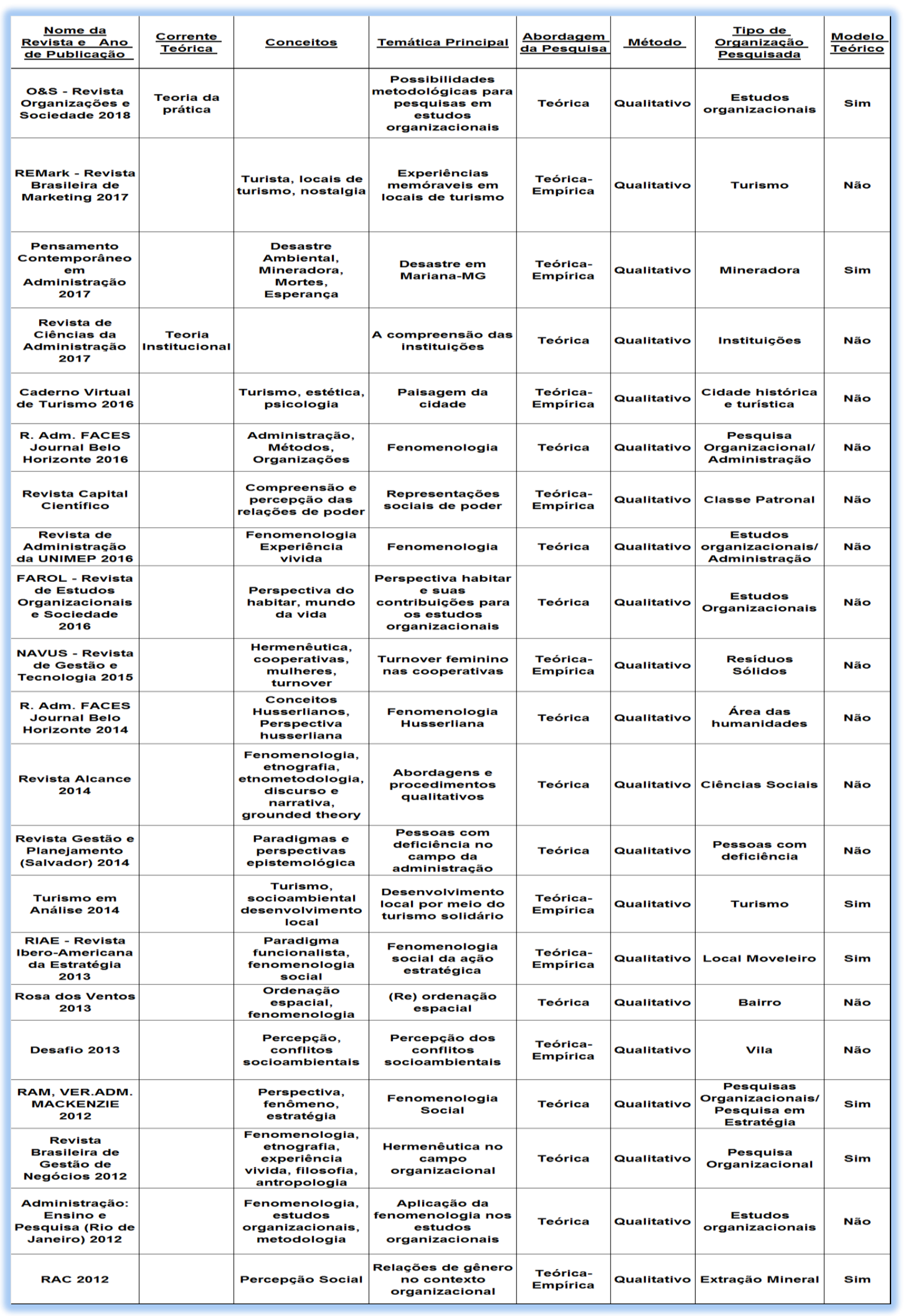




\begin{tabular}{|c|c|c|c|c|c|c|c|}
\hline$\frac{\begin{array}{l}\text { Nome da } \\
\text { Revista e ano ano de }\end{array}}{\text { Publicaçäo }}$ & Corrente Teórica & Conceitos & Temática Principal & $\frac{\text { Abordagem da }}{\text { Pesquisa }}$ & Método & $\begin{array}{l}\frac{\text { Tipo de }}{\text { Organizacăo }} \\
\text { Pesquisada }\end{array}$ & Modelo Teórico \\
\hline RAC 2011 & & $\begin{array}{l}\text { Contexto da Pós- } \\
\text { Graduação no Brasil }\end{array}$ & $\begin{array}{l}\text { Prática de ensino- } \\
\text { aprendizagem }\end{array}$ & Teórica-Empírica & Qualitativo & $\begin{array}{c}\text { Curso de Mestrado } \\
\text { em Adm }\end{array}$ & $\operatorname{sim}$ \\
\hline $\begin{array}{l}\text { CADERNOS } \\
\text { EBAPE.BR } 2010\end{array}$ & & $\begin{array}{l}\text { Conceitos Sobre } \\
\text { Fenomenologia como } \\
\text { Área da Fillosofia }\end{array}$ & $\begin{array}{c}\text { Principais } \\
\text { contribuicóes e } \\
\text { possibilidades da } \\
\text { fenomenologia para } \\
\text { os estudos } \\
\text { organizacionais }\end{array}$ & Teórica & Qualitativo & $\begin{array}{c}\text { Estudos } \\
\text { organizacionais }\end{array}$ & $\operatorname{sim}$ \\
\hline $\begin{array}{l}\text { REBRAE. Revista } \\
\text { Brasileira de } \\
\text { Estratégia 2011 }\end{array}$ & $\begin{array}{l}\text { Corrente teórica } \\
\text { schütziana }\end{array}$ & & $\begin{array}{c}\text { Formacão da } \\
\text { estratégia nas suas } \\
\text { atividades } \\
\text { empresariais }\end{array}$ & Teórica-Empírica & Qualitativo & $\begin{array}{l}\text { Setor de } \\
\text { restaurantes } \\
\text { de Salvador }\end{array}$ & $\operatorname{sim}$ \\
\hline $\begin{array}{l}\text { Revista Turismo } \\
\text { Visāo e Ação } 2011\end{array}$ & & $\begin{array}{l}\text { Conceitos de } \\
\text { Fenomenologia }\end{array}$ & $\begin{array}{l}\text { Método } \\
\text { fenomenológico } \\
\text { para o turismo } \\
\text { gastronômico }\end{array}$ & Teórica & Qualitativo & $\begin{array}{l}\text { Segmento de } \\
\text { turismo } \\
\text { gastronômico. }\end{array}$ & $\operatorname{sim}$ \\
\hline $\begin{array}{c}\text { Pensar Contábil } \\
2010\end{array}$ & & $\begin{array}{c}\text { Conceitos de } \\
\text { Contabilidade no } \\
\text { Sistema Jurídico } \\
\text { Tributário }\end{array}$ & $\begin{array}{l}\text { Contabilidade e } \\
\text { direito tributário }\end{array}$ & Teórica & Qualitativo & $\begin{array}{c}\text { Campo tributário e } \\
\text { contábil }\end{array}$ & sim \\
\hline $\begin{array}{l}\text { O\&S - Revista } \\
\text { Organizaçoss e } \\
\text { Sociedade 2018 }\end{array}$ & $\begin{array}{c}\text { Corrente teórica de } \\
\text { Guerreiro Ramos }\end{array}$ & & $\begin{array}{c}\text { Conceitos } \\
\text { fundamentais } \\
\text { fenomenológicos } \\
\text { que Guerreiro } \\
\text { Ramos usou }\end{array}$ & Teórica & Qualitativo & $\begin{array}{l}\text { Escritos de } \\
\text { Guerreiro Ramos }\end{array}$ & sim \\
\hline $\begin{array}{l}\text { Caderno Virtual de } \\
\text { Turismo } 2010\end{array}$ & $\begin{array}{c}\text { NĀO É } \\
\text { FENOMENOLOGIA }\end{array}$ & $\begin{array}{c}\text { NĀO É } \\
\text { FENOMENOLOGIA }\end{array}$ & $\begin{array}{c}\text { NĀO É } \\
\text { FENOMENOLOGIA }\end{array}$ & $\begin{array}{l}\text { NĀOÉÉ } \\
\text { FENOMENOLOGIA }\end{array}$ & $\begin{array}{c}\text { NĀO É } \\
\text { FENOMENOLOGIA }\end{array}$ & $\begin{array}{c}\text { NĀO É } \\
\text { FENOMENOLOGIA }\end{array}$ & $\begin{array}{c}\text { NÃO É } \\
\text { FENOMENOLOGIA }\end{array}$ \\
\hline $\begin{array}{l}\text { ADMINISTRACÃO } \\
\text { DA PESQUISA } \\
2010\end{array}$ & & $\begin{array}{l}\text { Conceitos de Método } \\
\text { Fenomenológico }\end{array}$ & $\begin{array}{c}\text { Abordagem } \\
\text { tradicional }\end{array}$ & Teórica & Qualitativo & $\begin{array}{c}\text { pesquisa } \\
\text { interpretativista }\end{array}$ & Não \\
\hline $\begin{array}{l}\text { RAU -Revista de } \\
\text { Administracăo da } \\
\text { UNIMEP 2009 }\end{array}$ & & $\begin{array}{l}\text { Conceitos de } \\
\text { interfaces entre } \\
\text { relaçōes sociais a } \\
\text { relaçōes de negócios }\end{array}$ & $\begin{array}{c}\text { Relaçōes entre as } \\
\text { variáveis sociais e } \\
\text { as variáveis de } \\
\text { negóclos em } \\
\text { governança e } \\
\text { inovação }\end{array}$ & Teórica & Qualitativo & $\begin{array}{c}\text { Interface das } \\
\text { relaçōes sociais e } \\
\text { das relaçōes de } \\
\text { negócios em redes, } \\
\text { no escopo } \\
\text { brasileiro }\end{array}$ & $\operatorname{sim}$ \\
\hline $\begin{array}{l}\text { CADERNOS } \\
\text { EBAPE } 2009\end{array}$ & $\begin{array}{c}\text { Corrente teórica } \\
\text { Teoria Critica }\end{array}$ & & $\begin{array}{c}\text { Elaborar uma critica } \\
\text { da concepçăo de } \\
\text { Guerreiro Ramos } \\
\text { nos estudos } \\
\text { organizacionais }\end{array}$ & Teórica & Qualitativo & $\begin{array}{c}\text { Estudos } \\
\text { organizacionais }\end{array}$ & $\operatorname{sim}$ \\
\hline RAE 2008 & & $\begin{array}{l}\text { Conceitos de } \\
\text { interpretativismo na } \\
\text { pesquisa do } \\
\text { consumidor }\end{array}$ & $\begin{array}{l}\text { Pesquisa } \\
\text { interpretativa do } \\
\text { consumidor }\end{array}$ & Teórica & Qualitativo & $\begin{array}{c}\text { Conversaçōes com } \\
\text { disciplinas das } \\
\text { Clências Humanas e } \\
\text { Sociais }\end{array}$ & $\operatorname{sim}$ \\
\hline $\begin{array}{c}\text { Revista } \\
\text { ADM.MADE } 2008\end{array}$ & $\begin{array}{c}\text { Corrente teórica de } \\
\text { Denzin (1989) }\end{array}$ & & $\begin{array}{l}\text { Pesquisa acadêmica } \\
\text { em marketing }\end{array}$ & Teórica & Qualitativo & $\begin{array}{c}\text { Pesquisa acadêmica } \\
\text { em marketing }\end{array}$ & $\operatorname{sim}$ \\
\hline $\begin{array}{l}\text { RAI-Revista de } \\
\text { Administracāao e } \\
\text { Inovaçâo } 2007\end{array}$ & & $\begin{array}{l}\text { Conceitos de Método } \\
\text { Fenomenológico }\end{array}$ & $\begin{array}{c}\text { Estratégia de } \\
\text { auxillar os } \\
\text { pesquisadores a } \\
\text { praticarem a } \\
\text { reducão } \\
\text { fenomenológica }\end{array}$ & Teórica-Empirica & Misto & $\begin{array}{l}\text { Empresas do setor } \\
\text { elétrico brasileiro }\end{array}$ & sim \\
\hline $\begin{array}{l}\text { Turismo - Visão e } \\
\text { Ação 2007 }\end{array}$ & & $\begin{array}{l}\text { Conceitos de bem } \\
\text { estar espiritual a } \\
\text { partir de quatro } \\
\text { dimensóes centrais }\end{array}$ & $\begin{array}{c}\text { Vivência do bem } \\
\text { estar espiritual } \\
\text { pelos } \\
\text { peregrinos } \\
\text { brasileiros do } \\
\text { Caminho de } \\
\text { Santiago de } \\
\text { Compostela }\end{array}$ & Teórica-Empírica & Qualitativo & $\begin{array}{c}\text { Peregrinos } \\
\text { brasileiros do } \\
\text { Caminho de } \\
\text { Santiago de } \\
\text { Compostela }\end{array}$ & sim \\
\hline $\begin{array}{l}\text { RAC-Eletrônica } \\
2007\end{array}$ & & $\begin{array}{c}\text { Conceitos de } \\
\text { identidade individual } \\
\text { e social }\end{array}$ & $\begin{array}{c}\text { Fenômeno } \\
\text { identidade, } \\
\text { estabelecendo } \\
\text { ligaçăo entre sua } \\
\text { dimensão social e } \\
\text { Individual. }\end{array}$ & Teórica-Empírica & Qualitativo & $\begin{array}{c}\text { Observaçōes em } \\
\text { feiras de produtos } \\
\text { orgânicos, } \\
\text { propriedades de } \\
\text { agricultores } \\
\text { famillares e } \\
\text { ecologistas }\end{array}$ & $\operatorname{sim}$ \\
\hline $\begin{array}{l}\text { Revista } \\
\text { Contabilidade \& } \\
\text { Finanças 2004 }\end{array}$ & $\begin{array}{l}\text { Teoria das } \\
\text { Representaçōes } \\
\text { Sociais }\end{array}$ & & $\begin{array}{c}\text { Estudantes } \\
\text { universitários e } \\
\text { profissionais } \\
\text { da área econômica }\end{array}$ & Teórica-Empírica & Misto & $\begin{array}{c}\text { Estudantes } \\
\text { universitários e } \\
\text { profissionais } \\
\text { da área econônica }\end{array}$ & $\operatorname{sim}$ \\
\hline $\begin{array}{c}\text { Cadernos } \\
\text { EBAPE.BR 2004 }\end{array}$ & $\begin{array}{c}\text { Corrente teórica } \\
\text { Fenomenologia em } \\
\text { Husseri }\end{array}$ & & $\begin{array}{l}\text { Essência da } \\
\text { fenomenologia }\end{array}$ & Teórica & Qualitativo & Universo Clentifico & $\operatorname{sim}$ \\
\hline $\begin{array}{l}\text { Revista Brasileira } \\
\text { de Gestão de } \\
\text { Negócios - } \\
\text { FECAP 2004 }\end{array}$ & $\begin{array}{c}\text { Corrente teórica de } \\
\text { MOW }\end{array}$ & & $\begin{array}{l}\text { Significado } \\
\text { atribuído ao } \\
\text { trabalho }\end{array}$ & Teórica-Empírica & Qualitativo & $\begin{array}{l}\text { Não especifica a } \\
\text { organização }\end{array}$ & $\operatorname{sim}$ \\
\hline $\begin{array}{c}\text { Revista } \\
\text { Catarinense da } \\
\text { Ciência Contabbil } \\
\text { CRCSC 2004 }\end{array}$ & & $\begin{array}{c}\text { Conceitos sobre } \\
\text { planejamento e } \\
\text { sistemas de } \\
\text { informaçōes da área } \\
\text { contábel }\end{array}$ & $\begin{array}{c}\text { Singularidades dos } \\
\text { processos } \\
\text { mercadológicos das } \\
\text { empresas } \\
\text { construtoras }\end{array}$ & Teórica-Empírica & Qualitativo & $\begin{array}{l}\text { Empresas de } \\
\text { construçäo civil }\end{array}$ & $\operatorname{sim}$ \\
\hline $\begin{array}{c}\text { RAE - Revista de } \\
\text { Administracaáo de } \\
\text { Empresas } 2002\end{array}$ & & $\begin{array}{c}\text { Conceitos sobre a } \\
\text { pesquisa } \\
\text { fenomenológica }\end{array}$ & $\begin{array}{c}\text { Procedimentos que } \\
\text { utilizam a } \\
\text { fenomenologia } \\
\text { como opcáa } \\
\text { metodológica }\end{array}$ & Teórica-Empírica & Qualitativo & $\begin{array}{c}\text { Universo Cientifico } \\
\text { para pesquisa de } \\
\text { marketing }\end{array}$ & $\operatorname{sim}$ \\
\hline $\begin{array}{c}\text { Revista de } \\
\text { Administraçăo } \\
2000\end{array}$ & & $\begin{array}{c}\text { Análise das } \\
\text { contribuiçóes } \\
\text { teóricas ao tema }\end{array}$ & $\begin{array}{c}\text { Distinguir a } \\
\text { orientacăo } \\
\text { epistemológica } \\
\text { baseada no } \\
\text { empirismo formal }\end{array}$ & Teórica & Qualitativo & Universo Cientifico & sim \\
\hline
\end{tabular}

Fonte: Elaborado pelas autoras, 2018 


\section{CONSIDERAÇÕES FINAIS}

A fenomenologia é uma ciência que estuda a essência do fenômeno por meio de uma consciência intencional. Esta veio em contraposição ao positivismo, uma vez que leva em consideração a percepção, a subjetividade e a experiência vivida das pessoas. É uma proposta metodológica de investigação do homem com o meio que o circunda, e quer definir as essências (da consciência e da percepção).

Através da sua filosofia, pretende-se relatar o espaço, o tempo e o mundo vivenciados pelos seres humanos, pois o conhecimento está na capacidade de perceber o que nos cerca, o que implica no processo de dar significados ao que foi assimilado pelos sentidos, para assim, realizar as conexões entre os objetos perceptíveis e vê-los como um todo (MERLEAU-PONTY, 1999).

Observa-se que o objetivo deste estudo é descrever a fenomenologia na abordagem da pesquisa científica, fazendo um levantamento dos artigos encontrados na base da SPELL nos anos 2000 a 2018, enfatizando que apesar do uso desse método ser bastante difícil e pouco comum nas investigações organizacionais da atualidade, este também é um desafio motivador para o alcance de conhecimentos de aspectos que ficam muitas vezes desconhecidos ou ocultos dentro de uma empresa. Conhecer o mundo vivido desses espaços através das investigações fenomenológicas vai muito além do fenômeno estudado e portanto, enriquece as pesquisas e os saberes.

Sendo assim, observou-se que a temática principal dos artigos foram estudos organizacionais, identificada com maior frequência nas publicações. As revistas que mais publicaram foram Cadernos EBAPE.BR e a RAC, e o ano com mais publicações foi 2016, e nota-se também que a Instituição de Ensino Superior que teve mais publicações foi a Universidade Federal de Ouro Preto de Minas Gerais (UFOP-MG), na qual encontram-se 10 (dez) publicações sobre fenomenologia. Nesta perspectiva, ressalva-se os autores Fernanda Maria Felicio Macedo e Diego Luiz Teixeira Boava que tiveram 6 (seis) estudos publicados na abordagem em questão.

Sobre o método utilizado nas pesquisas, dos 41 (quarenta e um) artigos, notou-se que, 39 (trinta e nove) são classificados como qualitativos e 2 (dois) misto, ou seja, utilizou-se o método qualitativo e quantitativo. Sobre a estruturação do referencial teórico dos estudos, 9 (nove) seguiram correntes teóricas e 32 (trinta e dois) usaram conceitos.

Desta forma, pode-se reforçar a ideia de Marconi e Lakatos (1999), que defendem que a pesquisa qualitativa tem como objetivo, analisar e interpretar aspectos mais profundos, descrevendo a complexidade do comportamento humano e ainda fornecendo análises mais detalhadas sobre as investigações, atitudes e tendências de comportamento.

Em relação à abordagem de pesquisa, 24 (vinte e quatro) artigos são teóricos e 17 (dezessete) artigos são teóricos-empíricos. Sobre o modelo teórico 26 (vinte e seis) artigos usaram um modelo teórico em sua estrutura e 15 (quinze) não usaram.

Sendo assim, a fenomenologia tende a ser complexa, pois não possui "dados acabados, prontos" e ainda está em constante estudo, é algo que foge da objetividade científica e por isso ainda causa muitas dúvidas e inseguranças em muitos pesquisadores. Por fim, cabe enfatizar que a fenomenologia permite vislumbrar novas possibilidades de leituras do mundo, sabendo que cada ser é único e singular. 


\section{REFERÊNCIAS}

BOAVA, D. L. T.; MACEDO, F. M. F. Contribuições da fenomenologia para os estudos organizacionais. Cadernos EBAPE.BR, v. 9, Ed. Especial, p. 469-487, 2011.

GODOI, C. K. et al. (Org.). Pesquisa Qualitativa em Estudos Organizacionais: Paradigmas, Estratégias e Métodos. São Paulo: Saraiva, 2006.

MARCONI, M. A; LAKATOS, E. M. Técnicas de pesquisa: planejamento e execução de pesquisas, amostragens e técnicas de pesquisas, elaboração, análise e interpretação de dados. 4. ed. São Paulo: Atlas, 1999.

MEDEIROS, M. L.; PASSADOR, J. L.; BECHELENI, D. G. A fenomenologia e a pesquisa em turismo: Reflexões para aplicação com base no turismo gastronômico. Turismo Visão e Ação. ISSN 1983-7151, v. 13, n. 1, p. 2-34, 2011.

MIRANDA, N. M. Percepção ambiental dos proprietários rurais do município de Palmas (TO): subsídios para o licenciamento ambiental. 2010. 128 f. Dissertação (Mestrado em Ciências do Ambiente) - Universidade Federal do Tocantins, Palmas, TO.

MOURA, M. C. C.; BITENCOURT, C. C. A articulação entre estratégia e o desenvolvimento de competências gerenciais. RAE-eletrônica. São Paulo, v. 5, n. 1, Art. 3, jan./jun. 2006.

PIMENTEL, R.; NOGUEIRA, E. E. S. Estudos baseados na prática: possibilidades metodológicas para pesquisas em estudos organizacionais. Revista Organizações \& Sociedade, v. 25, n. 86, p. 35-37, 2018.

PONTY-MERLEAU, M. Fenomenologia da percepção. Trad. Carlos Alberto Ribeiro Moura. São Paulo: Martins Fontes, 1999.

SANTOS, F. P.; SOUZA, L. B. Estudo da percepção da qualidade ambiental por meio do método fenomenológico. Mercator. Fortaleza, v.14, n.2, p. 57-74, 2015.

SIANI, S. R.; CORREA, D. A.; LAS CASAS, A. L. Fenomenologia, método fenomenológico e pesquisa empírica: $O$ instigante universo da construção do conhecimento esquadrinhada na experiência de vida. Revista da Administração da UNIMEP (RAU). ISSN: 1679-535, v.14, n. 1, p. 193-219, 2016.

SILVA, M. T. Uma análise crítica do método fenomenológico e da sua relação com as "Geografias" Humanistas. Geografia em Questão. ISSN 2178-234, v. 6, n. 2, p. 63-93, 2013.

SILVEIRA, R. Z. da; GUERRA, A. C; GONÇALVES, C. A. A Aplicação da fenomenologia nos estudos organizacionais do Brasil. Administração: Ensino e Pesquisa RAEP. Rio de Janeiro, v. 13, n. 2, p. 269-3, 2012.

SOUZA, L. B. Percepção ambiental e fenomenologia: possibilidades de adaptação do método e alguns exemplos de pesquisas. Desenvolvimento e Meio Ambiente (DMA). v.4, p. 297$314,2017$. 
SOUZA, L. B. Percepção ambiental e a fenomenologia de Husserl: um exercício de reaproximação. In: SILVA, V. C. P; CORCÍNIO JÚNIOR, G. (Orgs.) Natureza e representações imaginárias. Curitiba: Apris, p. 35-51, 2013. 